\title{
NORTH AMERICAN INSTITUTIONS MOST FREQUENTLY REPRESENTED IN HIGH-IMPACT LIBRARY JOURNALS
}

\author{
SCOTT SEAMAN \\ DEAN OF LIBRARIES \\ OHIO UNIVERSITY \\ ALDIN LIBRARY \\ ATHENS, OH 45701-2978 \\ SEAMAN@OHIO.EDU
}

\begin{abstract}
Five library journals were analyzed for North American institutional affiliation of authors between the years 2000 and 2005 to find the institutions most frequently represented. The five journals were selected for having consistent high impact factors over five years. Of those institutions represented in the five journals, less than ten percent of academic libraries accounted for nearly forty-two percent of all author affiliations in the five highest impact journals. A list of thirty-eight libraries - the top ten percent-was compiled and correlation analysis was performed to determine if any characteristics, such as size of professional staff, Association of Research Libraries (ARL) membership, or the presence of a PhD-granting library school influenced location in the ranking.
\end{abstract}

\section{Introduction}

Assessing faculty research productivity has been a preoccupation within academia for decades. Hundreds of studies counting faculty publications, including several within the field of librarianship, have appeared since the 1990s. While many libraries invest considerable resources in scholarly activities, it is unclear which institutions successfully foster publications in top-quality journals. That is, are there libraries whose faculty contribute to top-tier journals more frequently than others? This study examines five of the highest ranked library journals to determine which libraries' faculty regularly contribute scholarship.

For this study, five library journals were examined for the six years 2000 through 2005. The five journals - College \& Research Libraries, Journal of Academic Librarianship, Library Quarterly, Library \& Information Science Research, and Library Trends-were selected for having consistently high impact factors among library science journals. Each journal issue was examined for the primary and secondary author's institutional affiliation. The resulting data set of nearly 1,100 author affiliations representing 433 different institutions was sorted to identify those institutions most frequently represented in these journals. A list of thirty-eight different institutions - approximately the top ten percent - is compiled and correlation analysis was performed to determine if any characteristics, such as size of professional staff, Association of Research Libraries (ARL) membership, or the presence of a PhD-granting library school influenced the ranking among the thirty-eight institutions. 


\section{Literature Review}

The literature assessing faculty publication productivity is voluminous and sometimes highly debated. A.N. Zainab's excellent review of academic literature thoroughly covers the field until the late-1990s (Zainab, 2000). Rather than repeat that survey, this review will highlight only the more recent library-related publications pertinent to this study. One caution in reviewing this literature is that, because of the disparate populations and timeframes used, it is virtually impossible to compare the results of the different studies. Instead, it is more accurate to interpret the findings as complementing one another rather than building on one another.

The most common approach in ranking librarian publication rates is to count the publications of a specific population of authors such as all librarians at one institution, the faculty teaching in library school programs, etc. There are often debates as to what should be counted as a publication in these studies and, frequently, some proxy is added as a weight for publication quality. Less common is to analyze journal volumes - for example, College \& Research Libraries or the Journal of Academic Librarianship - to profile who or what is being published. Regardless of approach, most studies have used one of three methodologies: perception surveys, citation counts, or publication counts. Each of the three has advantages and disadvantages, and determining which is the better methodology depends on the population under review and the objective of the study.

Perception surveys solicit expert opinions on who are considered the top researchers, programs, or institutions within a particular field. These surveys can be relatively simple to implement and can capture subjective aspects that numerical counts miss. Expert judgments can, however, result in inaccurate measures of performance. Without clearly articulated criteria on what constitutes top-tier performance, perception studies may rank only the more visible rather than the more productive programs. Perhaps because of such limitations, recent studies have shifted away from perception studies to other methodologies.

A citation count, another common methodology, relies upon an index, such as the Social Sciences Citation Index, to determine which authors are most often cited. Citations, it is reasoned, are indicators of the value and impact of another's work and serve as a thirdparty endorsement of quality. Those authors most cited, it is asserted, are likely to be producing the highest quality research. A common criticism of such counts is that they include self-citations or citations to close colleagues. In addition, some references are intentionally made to highlight poor quality or infamous work. When working through an index count, there is no way to completely remove gratuitous citations or citations to substandard work. Consequently, the count can be exaggerated for some authors leading to a false impression of the influence of their work.

Publication counts have been the methodology most used in librarianship to assess productivity. This approach typically tallies articles either by examining vitae or by performing searches in such databases as the Social Sciences Citation Index or Library Literature. Adjustments are sometimes included to quantify quality, but such attempts 
are frequently criticized for lacking subtlety and accuracy. Richard Hart, for example, employed publication counts from vitae with a follow-up survey to profile fifty-nine librarians at the Pennsylvania State University Libraries. He found those faculty had published an average of 3.4 refereed articles and 2.2 nonrefereed articles, one book chapter, and one conference proceeding (Hart, 1999). Publication activities of faculty teaching in library school programs have been analyzed several times, most recently in 2000 by John Budd (Budd, 2000). He used the Social Sciences Citation Index to generate publication counts from 1993 to 1998 and then calculated individual and institutional activity. He found the library schools at Hawaii, Tennessee, and Missouri to have had the most per-capita publications and articles from Rutgers, University of California at Berkeley, and Indiana were the most frequently cited.

In another example of publication counts, John Budd performed three separate studies of institution-wide publication productivity for colleges and universities whose libraries are members of ARL or the Association of College and Research Libraries (ACRL) (Budd, 1995; Budd, 1999; Budd, 2006). He published studies for the time periods 1991-1993 and 1995-1997 and then a third in 2002-2004 that included a comparison of all three time periods. Using publication counts derived from the Social Sciences Citation Index, Science Citation Index, and the Arts \& Humanities Citation Index, Budd ranked faculty publishing activity and then correlated how the rankings compared with library budgetary support. Throughout the three studies, the institutions ranking in the top twenty of faculty publications remained surprisingly consistent. Of those affiliated with ARL, ten of the top twenty were consistently represented in all three time periods. Of these, Harvard, Johns Hopkins, and Washington University faculty ranked among the top five in each study. Of those affiliated with ACRL, fifteen of the top twenty were ranked in each of the three studies. Among the ACRL institutions, Tufts, Carnegie Mellon, and Virginia Commonwealth University were consistently ranked in the top five in each time period studied. Budd found a high correlation between per capita publication activity and per capita library expenditures for both ARL and ACRL institutions.

Mickey Zemon and Alice Bahr measured publications of all college librarians published in the Journal of Academic Librarianship and College \& Research Libraries from 1986 to 1996 (Zemon \& Baber, 1998). Using publication counts and a targeted survey, they determined that college librarian authors tend to come from prestigious institutions in Midwest or Northeast, be directors or reference librarians, and, overall, publish less than their university counterparts. In a follow-up study utilizing the same data from Journal of Academic Librarianship and College \& Research Libraries, Bahr and Zemon examined evidence of co-authorship among college librarians (Zemon \& Baber, 2000). They found that co-authorship has increased significantly in the past decades, that the Journal of Academic Librarianship has more evidence of co-authorship than College \& Research Libraries, and that university librarians tend to coauthor more than college librarians.

Rather than analyze a specific population of librarians, Ann C. Weller, Julie M. Hurd, and Stephen E. Wiberly, Jr.(1999) counted publications in thirty-two journals published between 1993 and 1997 to produce a ranked list of highly productive libraries. Weller et al. (1999) found that most authors (seventy-eight percent) published one peer-reviewed 
article in one of the thirty-two journals during the five year period and that forty-four percent of the articles had more than one author. Those libraries most frequently represented were Pennsylvania State University, Cornell University, and the University of Illinois at Urbana-Champaign. In a 2006 follow-up study of the same thirty-two journals covering the years 1998 through 2002, Stephen E. Wiberley, Jr., Julie M. Hurd, and Ann C. Weller (2006) also found that most authors (seventy-eight percent) published one peer-reviewed article in one of the thirty-two journals during the five-year period. Co-authorship remained virtually the same with forty-one percent of articles having more than one author. But those libraries identified as the top five in productivity shifted to Texas A\&M University, Pennsylvania State University, University of Illinois at Chicago, University of Illinois at Urbana Champaign, and Ohio State University.

Whatever the source for the counts - databases, vitae, or journal issues - the topics of comprehensiveness and quality have been frequently debated. In any count of either publications or citations, the databases used will greatly impact the results. Most studies use only one database, the Social Sciences Citation Index, as a resource. Yet Meho and Kristina Spurgin (2005 demonstrated that no single citation index fully covers the library and information science literature. They argue for using between four and ten databases for more comprehensive coverage of the discipline. While using multiple databases would greatly expand the number of books and nonrefereed articles included in the analysis, there are, however, diminishing returns in trying to cover the literature exhaustively. As the coverage expands, the quality may deteriorate. Marcia Bates observed that if "

minor publications, such as book reviews, are counted with major publications, such as journal articles and refereed books, the sheer numbers of the smaller publications may obscure important differences between programs on the more substantial publication measures, and thus may distort rankings (Bates, 1998, p. 197).

Consequently, balancing the practicality of compiling the counts, the ability to sample the published literature in such a way as to fairly represent the breadth of the discipline, and to include only high-quality publications is a challenge these studies have not resolved.

\section{Methodology}

Rather than examine a specific population of librarians, as did Hart and Budd, this study examines representative library science journals to determine which institutions are most frequently represented. Institutions were chosen rather than individuals because if librarians publish an average of one peer-reviewed article every five years, as Weller et al.'s (1999) findings suggest, too many years would have to be reviewed to be meaningful. A period of six years was chosen-2000 to 2005-as the most recent data available to capture the most recent trends.

To identify those libraries producing the highest quality publications, the author reduced hundreds of possible library science journals to five that have arguably the highest impact in the field of librarianship. A high impact factor indicates that, overall, the journal's content is cited frequently. The more frequently a journal has been cited by researchers in their writing, the higher the impact factor. High citation rates, it can be argued, represent independent endorsement of quality by the researchers who have thoroughly 
examined the literature in the discipline. It is therefore assumed that by limiting this analysis to only those journals with the highest impact factors, those libraries producing high quality research will be identified.

The titles were arrived at by first limiting potential journals to only those included in Thomson Scientific's (formerly ISI) Journal Citation Reports (JCR). Average impact factors for the six years 2000 and 2005 were calculated for each of the fifty-five titles indexed in the Information Science and Library Science subject category. From that ranked list, the five library journals that represented the most consistently high impact factors were selected. Articles in each of the five journal titles were then analyzed for institutional affiliation between the years 2000 and 2005 to create a ranked list of most frequently represented libraries.

\section{Impact Factors}

Because this research relies upon impact factors to determine which journals to analyze, a brief summary of impact factors is appropriate. Thomson Scientific's impact factor is the best known and most frequently used measure for journal evaluation. It assesses the extent to which recent articles published in the journal literature are being cited. The impact factor is often generalized as the average number of times a journal's article has been cited even though a specific article may have been cited far more or fewer times. The Thomson Scientific website explains that the journal impact factor is calculated by dividing the number of citations in the JCR year by the total number of articles published in the two previous years. An impact factor of 1.0 means that, on average, the articles published one or two year[s] ago have been cited one time. An impact factor of 2.5 means that, on average, the articles published one or two year[s] ago have been cited two and a half times (Thompson, 2006a, np).

Thomson Scientific social sciences edition categorizes journals into fifty-five disciplinary ranges such as women's studies, psychiatry, industrial relations and labor, and information science and library science. Included in the information science and library science classification are fifty-five journal titles ranging from MIS Quarterly to College \& Research Libraries (Thompson, 2006b). Although not all journals within librarianship are included in JCR, many of the most respected are represented. The scope notes explain that "information science and library science" includes journals on

a wide variety of topics, including bibliographic studies, cataloging, categorization, database construction and maintenance, electronic libraries, information ethics, information processing and management, interlending, preservation, scientometrics, serials librarianship, and special libraries (Thompson, 2006c, np.).

This definition is so wide-ranging that, within the fifty-five journals, there are titles specializing in computer science, geography, management information systems, as well as librarianship. Only about half of the fifty-five titles are predominantly authored by academic librarians or library school faculty. The remaining titles are predominantly authored by computer science or management information systems professionals. In fact, of the fifty-five titles included in the classification of "information science and library 
science," twenty-one are not indexed by Library Literature and would be considered out of scope of librarianship by most practitioners.

A high-impact factor indicates that the articles within a publication are frequently cited and suggests high esteem for that journal within the research community. Equating high impact factors with high quality is controversial because it assumes that citation frequency accurately measures a journal's importance. While there is anecdotal evidence for such an assumption, some scholars argue that such a link has never been proven and that impact factors - and citation analysis generally_oversimplifies complex judgments to the detriment of substantive analysis of research influence (Joint Committee on Quantitative Assessment, 2008). According to Thomas Nisonger (2004), who summarizes the criticisms, impact factors can be problematic because they are limited to citations from journals indexed in the Thomson databases, data is not available for humanities journals, there have been instances of errors in the Thomson Scientific's databases, and citation practices in certain disciplines can negatively impact accuracy of the counting. Recognizing such weaknesses, however, Nisonger points out that impact factors are well-established, easily understood objective calculations that are updated annually. Moreover, impact factors normalize for the age and size of journals. Finally, while there have been innumerable suggestions about how to improve their accuracy, nothing has replaced impact factors as indicators of journal influence (Nisonger, 2004). Imperfect as they might be, impact factors are frequently used as a rough estimate of publication quality.

Journal impact factors are calculated annually and can vary considerably from year to year. For example Journal of Information Technology, , had an impact factor of 1.260 in $2002,0.641$ in 2003, and 1.543 in 2005. Depending upon the year chosen, that journal ranked either $23^{\text {rd }}(2003)$ or $8^{\text {th }}(2005)$ of the fifty-five journals in the category. Consequently, a single year's impact-factor ranking cannot accurately represent a journal's influence on a field over time. Thomson Scientific suggests calculating a fiveyear average impact factor in order to provide a better measure of a journal's contribution over time (Thompson, 2006d)

\section{Journal Selection}

To identify those library science journals with consistently high impact factors, the author used the Thomson Scientific instructions to calculate average journal impact factors for each of the fifty-five titles for the years 2000 and 2005. Three titles, however, did not have impact factors for all of the six years between 2000 and 2005. Information Research and portal: Libraries and the Academy had impact factors for only 2004 and 2005; Journal of the Medical Library Association had impact factors for only 2003 through 2005. While portal is a relatively new title for which impact factors could not be calculated earlier than 2004. It is unclear why Information Research (which began in 1976) and Journal of the Medical Library Association (which began in 1911) were missing impact factors for these dates. It is possible that title changes affected these journals impact factors. Because of the incomplete data, these three titles were excluded from the analysis. Two additional titles, Zeitschrift fuer Bibliothekswesen und Bibliographie and Library and Information Science, were removed from the analysis 
because nearly all of their articles are published in German or Japanese. Because this study was interested primarily in publications of North American librarians, journals published primarily outside the potential capture of North American library research were excluded from the study.

Because the JCR category of information science and library science includes titles that are not authored primarily by librarians, the author reviewed the contents of each journal title to determine if the authors were from the library, computer science, management information systems, or some other community. Those journals authored primarily by librarians were labeled "library science" while others were labeled "information science." This process was clearly subjective. Yet while there was some authorship by librarians in a few of the titles labeled "information science", librarians constituted a clear minority of writers during the period of 2000 and 2005. Those titles not authored primarily by librarians were excluded from the analysis.

The data in Table 1 ranks the fifty titles by their average five-year impact factor as calculated by the author.

\begin{tabular}{|c|c|c|c|}
\hline \multicolumn{4}{|c|}{$\begin{array}{c}\text { TABLE } 1 \\
\text { Thomson Scientific Journal Citation Reports } \\
\text { Social Sciences Edition } \\
\text { 2000-2005 Average Journal Impact Scores } \\
\text { Subject Category: Information Science and Library Science }\end{array}$} \\
\hline $\begin{array}{l}\text { Journal Citation Reports } \\
\text { Journal Title Abbreviation }\end{array}$ & ISSN & $\begin{array}{c}2000-2005 \\
\text { Journal } \\
\text { Average Impact } \\
\text { Factor }\end{array}$ & Category \\
\hline MIS QUART & $0276-7783$ & 3.0682 & Information Science \\
\hline ANNU REV INFORM SCI & $0066-4200$ & 2.4672 & Information Science \\
\hline J AM MED INFORM ASSN & $1067-5027$ & 2.2170 & Information Science \\
\hline INFORM SYST RES & $1047-7047$ & 1.9852 & Information Science \\
\hline J AM SOC INF SCI TEC & $1532-2882$ & 1.7112 & Information Science \\
\hline J DOC & 0022-0418 & 1.5534 & Information Science \\
\hline INFORM MANAGE-AMSTER & $0378-7206$ & 1.5164 & Information Science \\
\hline INFORM PROCESS MANAG & $0306-4573$ & 1.4098 & Information Science \\
\hline SCIENTOMETRICS & $0138-9130$ & 1.1440 & Information Science \\
\hline COLL RES LIBR & 0010-0870 & 1.1260 & Library Science \\
\hline INT J GEOGR INF SCI & $1365-8816$ & 1.1020 & Information Science \\
\hline J MANAGE INFORM SYST & $0742-1222$ & 1.0532 & Information Science \\
\hline J INF TECHNOL & $0268-3962$ & 0.9678 & Information Science \\
\hline J INF SCI & $0165-5515$ & 0.9000 & Information Science \\
\hline J HEALTH COMMUN & $1081-0730$ & 0.8752 & Information Science \\
\hline INFORM SOC & $0197-2243$ & 0.8090 & Information Science \\
\hline
\end{tabular}




\begin{tabular}{|c|c|c|c|}
\hline J ACAD LIBR & 0099-1333 & 0.7220 & Library Science \\
\hline LIBR INFORM SCI RES & 0740-8188 & 0.6700 & Library Science \\
\hline GOV INFORM Q & $0740-624 \mathrm{X}$ & 0.6280 & Information Science \\
\hline LIBR QUART & 0024-2519 & 0.6116 & Library Science \\
\hline SOC SCI COMPUT REV & $0894-4393$ & 0.5940 & Information Science \\
\hline INT J INFORM MANAGE & $0268-4012$ & 0.5876 & Information Science \\
\hline LIBR TRENDS & 0024-2594 & 0.5526 & Library Science \\
\hline TELECOMMUN POLICY & 0308-5961 & 0.5392 & Information Science \\
\hline LIBR RESOUR TECH SER & $0024-2527$ & 0.4854 & Information Science \\
\hline INFORM SYST J & $1350-1917$ & 0.4560 & Information Science \\
\hline ONLINE INFORM REV & $1468-4527$ & 0.4476 & Information Science \\
\hline RESTAURATOR & 0034-5806 & 0.4318 & Information Science \\
\hline REF USER SERV Q & $1094-9054$ & 0.4230 & Information Science \\
\hline LAW LIBR J & $0023-9283$ & 0.4218 & Library Science \\
\hline ASLIB PROC & $0001-253 X$ & 0.4122 & Information Science \\
\hline KNOWL ORGAN & 0943-7444 & 0.3824 & Information Science \\
\hline ONLINE & $0146-5422$ & 0.3604 & Information Science \\
\hline J LIBR INF SCI & 0961-0006 & 0.3506 & Library Science \\
\hline SCIENTIST & 0890-3670 & 0.3418 & Information Science \\
\hline RES EVALUAT & 0958-2029 & 0.3278 & Information Science \\
\hline INTERLEND DOC SUPPLY & $0264-1615$ & 0.3090 & Library Science \\
\hline PROGRAM-ELECTRON LIB & 0033-0337 & 0.3060 & Library Science \\
\hline LIBR COLLECT ACQUIS & $1464-9055$ & 0.2868 & Library Science \\
\hline SOC SCI INFORM & 0539-0184 & 0.2764 & Information Science \\
\hline ELECTRON LIBR & $0264-0473$ & 0.2360 & Library Science \\
\hline LIBR J & $0363-0277$ & 0.2344 & Library Science \\
\hline LIBRI & $0024-2667$ & 0.2214 & Library Science \\
\hline INFORM TECHNOL LIBR & $0730-9295$ & 0.2192 & Library Science \\
\hline J SCHOLARLY PUBL & $1198-9742$ & 0.1998 & Information Science \\
\hline CAN J INFORM LIB SCI & 1195-096X & 0.1780 & Library Science \\
\hline J GOV INFORM & $1352-0237$ & 0.1464 & Information Science \\
\hline J INFORM ETHICS & $1061-9321$ & 0.1190 & Information Science \\
\hline ECONTENT & $1525-2531$ & 0.0946 & Information Science \\
\hline P ASIST ANNU MEET & 0044-7870 & 0.0198 & Information Science \\
\hline
\end{tabular}

The five titles in bold represent the "library science" journals with the highest five-year average impact factor. The five "library science" titles with the highest average journal impact factors for 2000 through 2005 were College \& Research Libraries with an average impact factor of 1.1260, the Journal of Academic Librarianship with an average 
impact factor of 0.7220, Library \& Information Science Research with an average impact factor of 0.6700, Library Quarterly with an average impact factor of 0.6110, and Library Trends with an average impact factor of 0.5526.

Interestingly, this list closely corresponds to journal perception studies. In 1985, an influential perception study of the library literature was performed by David Kohl and Charles Davis in which they surveyed library deans and directors soliciting opinions as to which library journals were perceived to be most prestigious (Kohl, 1985). That study was most recently replicated in 2005 by Thomas Nisonger and Charles Davis (2005) who surveyed ARL deans and directors and LIS deans, asking them to rank seventy-one LIS journals according to their perceived prestige in terms of value for tenure and promotion. Finding considerable continuity between the 1985 and 2005 rankings, the authors computed that College \& Research Libraries, Library Trends, the Journal of Academic Librarianship, and Library Quarterly were ranked highest by ARL directors while library school deans ranked Journal of the American Society for Information Science and Technology, Library Quarterly, and Library \& Information Science Research among the most prestigious.

\section{Data Collection}

Rather than taking a random sample of articles, a graduate student examined every article from each issue of the five journals during the five-year span to record the primary and any secondary author. This represented thirty issues of College \& Research Libraries, thirty issues of Journal of Academic Librarianship, twenty issues of Library \& Information Science Research, twenty issues of Library Quarterly, and twenty issues of Library Trends. The data in Tables 2 and 3 are a sample section of the lengthy spreadsheet that was compiled from this process. 


\begin{tabular}{|c|c|c|c|c|}
\hline \multicolumn{5}{|c|}{$\begin{array}{c}\text { TABLE } 2 \\
\text { Sample Spreadsheet Section } \\
\text { Institutional Affiliation } \\
\text { Library Trends } \\
\text { Sorted by Volume and Issue }\end{array}$} \\
\hline Journal & Year & Volume & Issue & Author Institutional Affiliation \\
\hline LIBR TRENDS & 2005 & 54 & 1 & National Library of the Netherlands \\
\hline LIBR TRENDS & 2005 & 54 & 1 & National Library of Australia \\
\hline LIBR TRENDS & 2005 & 54 & 1 & Bibliotheque Nationale de France \\
\hline LIBR TRENDS & 2005 & 54 & 1 & Bibliotheque Nationale de France \\
\hline LIBR TRENDS & 2005 & 54 & 1 & National Library of New Zealand \\
\hline LIBR TRENDS & 2005 & 54 & 1 & Florida Center for Library Automation \\
\hline LIBR TRENDS & 2005 & 54 & 1 & Library of Congress \\
\hline LIBR TRENDS & 2005 & 54 & 1 & Harvard University \\
\hline LIBR TRENDS & 2005 & 54 & 1 & Data Intensive Computing Environments \\
\hline LIBR TRENDS & 2005 & 54 & 1 & Library of Congress \\
\hline LIBR TRENDS & 2005 & 54 & 2 & Florida State University \\
\hline LIBR TRENDS & 2005 & 54 & 2 & University of Tennessee Knoxville \\
\hline LIBR TRENDS & 2005 & 54 & 2 & University of California Los Angeles \\
\hline LIBR TRENDS & 2005 & 54 & 2 & University of California Los Angeles \\
\hline LIBR TRENDS & 2005 & 54 & 2 & Syracuse University \\
\hline LIBR TRENDS & 2005 & 54 & 2 & International Children's Digital Library \\
\hline LIBR TRENDS & 2005 & 54 & 2 & International Children's Digital Library \\
\hline LIBR TRENDS & 2005 & 54 & 2 & University of Maryland College Park \\
\hline LIBR TRENDS & 2005 & 54 & 2 & University of Maryland College Park \\
\hline LIBR TRENDS & 2005 & 54 & 2 & University of Maryland College Park \\
\hline LIBR TRENDS & 2005 & 54 & 2 & Rutgers \\
\hline LIBR TRENDS & 2005 & 54 & 2 & Pratt Institute \\
\hline LIBR TRENDS & 2005 & 54 & 2 & State University of New York Buffalo \\
\hline LIBR TRENDS & 2005 & 54 & 2 & McGill University \\
\hline LIBR TRENDS & 2005 & 54 & 2 & McGill University \\
\hline
\end{tabular}




\begin{tabular}{|c|c|c|c|c|}
\hline \multicolumn{5}{|c|}{$\begin{array}{c}\text { TABLE 3 } \\
\text { Sample Spreadsheet Section } \\
\text { Author Institutional Affiliation } \\
\text { All Journals Combined } \\
\text { Sorted by Institutional Affiliation }\end{array}$} \\
\hline Journal & Year & \begin{tabular}{|l|} 
Volume \\
\end{tabular} & Issue & Author Institutional Affiliation \\
\hline LIBR TRENDS & 2003 & 51 & 4 & CLIR \\
\hline LIBR TRENDS & 2003 & 52 & 1 & CLIR \\
\hline LIBR INFORM SCI RES & 2004 & 26 & 1 & Curtin University of Technology \\
\hline COLL RES LIBR & 2000 & 61 & 6 & Dalhousie University \\
\hline LIBR INFORM SCI RES & 2000 & 22 & 3 & Dalhousie University \\
\hline COLL RES LIBR & 2001 & 62 & 4 & Dalhousie University \\
\hline LIBR TRENDS & 2005 & 54 & 1 & Data Intensive Computing Environments \\
\hline J ACAD LIBR & 2005 & 31 & 5 & De Montfort University \\
\hline COLL RES LIBR & 2002 & 63 & 3 & Denison University \\
\hline LIBR TRENDS & 2000 & 49 & 2 & Digital Library Federation \\
\hline COLL RES LIBR & 2001 & 62 & 6 & Dominican University \\
\hline LIBR TRENDS & 2003 & 51 & 4 & Dominican University \\
\hline LIBR INFORM SCI RES & 2001 & 23 & 2 & Dominican University \\
\hline LIBR INFORM SCI RES & 2002 & 24 & 4 & Dowling College \\
\hline LIBR TRENDS & 2002 & 51 & 3 & Drexal University \\
\hline LIBR INFORM SCI RES & 2002 & 24 & 4 & Drexel University \\
\hline LIBR INFORM SCI RES & 2003 & 25 & 2 & Drexel University \\
\hline LIBR INFORM SCI RES & 2005 & 27 & 2 & Drexel University \\
\hline LIBR INFORM SCI RES & 2004 & 26 & 4 & Duksung Women's University \\
\hline LIBR INFORM SCI RES & 2005 & 27 & 2 & Duksung Women's University \\
\hline LIBR INFORM SCI RES & 2003 & 25 & 1 & EASLIS Makarere University \\
\hline COLL RES LIBR & 2000 & 61 & 4 & East Carolina University \\
\hline COLL RES LIBR & 2005 & 66 & 2 & East Carolina University \\
\hline J ACAD LIBR & 2000 & 26 & 3 & East Carolina University \\
\hline LIBR TRENDS & 2004 & 52 & 4 & East Carolina University \\
\hline COLL RES LIBR & 2003 & 64 & 2 & East Carolina University \\
\hline LIBR TRENDS & 2002 & 51 & 3 & Edith Cowan University \\
\hline COLL RES LIBR & 2000 & 61 & 5 & Emerson College \\
\hline COLL RES LIBR & 2005 & 66 & 5 & Emerson College \\
\hline
\end{tabular}

From each article, the student noted the author's institutional affiliation for up to two authors. If both authors were from the same institution, that institution was counted twice. If they were from different institutions, each institution was counted once. An article was defined as a full-length research-orientated manuscript. Editorials, columns, book reviews, letters, introductions to issues, and news pieces were excluded. While manuscripts for College \& Research Libraries, Journal of Academic Librarianship, Library \& Information Science Research, and Library Quarterly are unsolicited and peerreviewed, it is important to note that manuscripts for Library Trends are invited and 
editorially reviewed. While this is an important difference in publication practice, it does not affect citation rates. Because citation rates ranked Library Trends in the top five, the title was included in the study even though its review policies differ from the others.

Affiliation was recorded at the campus level. For the University of California, for example, the Los Angeles campus was counted separately from the Berkeley campus. Some institutional titles were, however, inconsistent. For example, City University of New York Baruch was sometimes listed only as Baruch College. Such rare occurrences were normalized by this author.

Any kind of affiliation was included in the count whether it was with an institute, consulting firm, academic library, public library, library utility, or automation vendor. In some instances, particularly for library school faculty, the citing of institutional affiliation was inconsistent. These faculty frequently simply cited the institution, such as the University of Toronto or UCLA, rather than the library school as their affiliation. This made it impossible to accurately determine if the author was a practitioner in that institution's academic library or a faculty member in the library school. Consequently, no attempt was made to separate library school faculty from practitioners.

Finally, in fifteen cases, the author's institutional affiliation could not be identified, and these were excluded from the analysis.

\section{Results}

This information was recorded in a spreadsheet and then sorted by institutional affiliation. The number of times each institution was represented was then rather laboriously counted and then ranked. Because one article may have up to two institutional affiliations, the number of affiliations does not necessarily correspond with the number of articles. The number of affiliations does, however, correspond with the number of authors.

With the fifteen unknown affiliations removed, there were 1,084 author affiliations for the five volumes of the five journal titles. Of the 1,084 affiliations, 433 different institutions were represented, demonstrating that the five journals published articles from a relatively broad range of institutions during that five-year period. Most institutions, however, were represented only once or twice in the six years. Three hundred thirty-six of the 433 institutions - or seventy-eight percent — were represented only once or twice. Only twenty-two percent of all institutions were represented more than twice. About ninety percent, or 395 of the institutions published fewer than six articles. The remaining ten percent - thirty-eight academic libraries - were represented 456 times of the 1,084 affiliations recorded. That is, of those published in the five journals, ten percent of academic libraries accounted for nearly forty-two percent of all author affiliations in the five highest impact journals between 2000 and 2005.

The number of manuscripts rejected by these five journals or how many different institutions those rejected manuscripts were from is not known. Clearly, a handful of libraries repeatedly successfully navigated the acceptance process of these top-tier journals. That four of the five journals has a double-blind review process argues against

$\operatorname{Pg} 12$ 
any bias. It is reasonable, instead, to conclude that these institutions have a history, at least between 2000 and 2005, of publishing high quality research.

Table 4 lists the thirty-eight institutions with the number of times each was represented in the five journals.

\begin{tabular}{|l|r|}
\hline \multicolumn{2}{|c|}{ TABLE 4 } \\
Top Ten Percent Most Frequently Represented Institutional \\
Affiliations All Institutions Combined n=38
\end{tabular}

Source: Blixrud, J.C. (2000). SPEC Kit 257: The M.L.S. Hiring Requirement. 
Association of Research Libraries, Office of Leadership and Management Services, p. 19.

Table 5 details the institutional affiliations, the occurrences of articles within the journals, whether the institution is an ARL, whether the institution offers a PhD in library and information science, and the number of professional staff in the library. Large academic libraries dominate the list with eighty-two percent being members of ARL and fifty-five percent of these institutions hosting a PhD-granting library school program. The average number of library professional staff at each institution in 2004 was 103. There are, however, libraries among the top ten percent that are not members of ARL, that are without large professional staff, and that do not host library schools. That the range of occurrences, from six to twenty-seven, is considerable also suggests significant differences among the libraries. It is interesting to note that, particularly in the bottom half of the data in Table 4, the number of occurrences is relatively low. That is, those institutions are represented with only six or seven affiliations in the five-year period. A single highly productive author may be responsible for a high percentage of the occurrences for those institutions. So the appearance of such libraries may represent the success of a single author rather than the quality of an entire program.

Tenure is common among the predominantly ARL members libraries listed in Table 4. Yet while tenure requirements might increase a library's publication count, it will not necessarily increase a library's publication quality. Whether an institution's librarians regularly publish in influential journals is not dependent upon the presence of tenure. Of the ten top institutions listed in Table 4, three do not offer tenure for practitioners (Florida State, University of California Los Angeles, and the University of Western Ontario), four offer tenure (University of Illinois Chicago, University of Illinois Urbana, Texas A\&M, and Rutgers), and three offer variations of continuing appointments (University of Toronto, University of Maryland College Park, and University of North Carolina Chapel Hill) (Blixrud, 2000, p. 19). Clearly there are libraries that are frequently represented in high-impact journals and, presumably, have a powerful influence on the research within librarianship, that do not offer tenure.

Possible ARL membership, the presence of a PhD-granting library school, and the number of professional staff in 2004 were compiled for each library from ALA and ARL websites as well as ACRL printed statistics (Association of Research Libraries, 2006a; Association of Research Libraries, 2006b; American Library Association, 2006; Association of College and Research Libraries, 2005a; Association of College and Research Libraries, 2005b). Neither Simmons College nor Suffolk University is a member of ARL nor do they contribute statistics to ACRL. These two institutions were, consequently, excluded from the analysis. 


\begin{tabular}{|c|c|c|c|c|}
\hline \multicolumn{5}{|c|}{$\begin{array}{c}\text { TABLE 5 } \\
\text { Top Ten Percent } \\
\text { Most Frequently Represented Institutional Affiliations } \\
\text { ARL and ACRL Members Only } \\
\text { Institutional Profile } \\
n=36\end{array}$} \\
\hline Author Institutional Affiliation & Occurrences & $\begin{array}{c}\text { ARL } \\
\text { Membership } \\
(1=\text { Yes, 0=No) }\end{array}$ & $\begin{array}{c}\text { LIS PhD } \\
(1=\text { Yes, } 0=\text { No) }\end{array}$ & $\begin{array}{c}2004 \\
\text { Professional } \\
\text { Staff }\end{array}$ \\
\hline Florida State University & 27 & 1 & 1 & 112 \\
\hline University of Toronto & 26 & 1 & 1 & 190 \\
\hline University of California Los Angeles & 24 & 1 & 1 & 152 \\
\hline University of Illinois Chicago & 24 & 1 & 0 & 74 \\
\hline University of Illinois Urbana & 24 & 1 & 1 & 186 \\
\hline University of Western Ontario & 22 & 1 & 1 & 63 \\
\hline Texas A\&M University & 19 & 1 & 0 & 122 \\
\hline Rutgers, The State University of New Jersey & 17 & 1 & 1 & 105 \\
\hline University of Maryland College Park & 17 & 1 & 1 & 121 \\
\hline University of North Carolina Chapel Hill & 16 & 1 & 1 & 141 \\
\hline Syracuse University & 12 & 1 & 1 & 67 \\
\hline University at Albany, SUNY & 11 & 1 & 0 & 60 \\
\hline University of Wisconsin Madison & 11 & 1 & 1 & 217 \\
\hline Indiana University Bloomington & 10 & 1 & 1 & 164 \\
\hline University of Oklahoma & 10 & 1 & 0 & 60 \\
\hline University of Washington & 10 & 1 & 1 & 137 \\
\hline Wayne State University & 10 & 1 & 0 & 106 \\
\hline McGill University & 9 & 1 & 1 & 65 \\
\hline Ohio State University & 9 & 1 & 0 & 121 \\
\hline Pennsylvania State University Park & 9 & 1 & 0 & 153 \\
\hline University at Buffalo, SUNY & 9 & 1 & 0 & 134 \\
\hline University of Missouri Columbia & 9 & 1 & 1 & 55 \\
\hline University of Pittsburgh & 9 & 1 & 1 & 118 \\
\hline Yale University & 9 & 1 & 0 & 239 \\
\hline Cornell University & 8 & 1 & 0 & 124 \\
\hline University of Colorado Boulder & 8 & 1 & 0 & 50 \\
\hline University of Alberta & 7 & 1 & 1 & 80 \\
\hline University of Arizon Tucson & 7 & 1 & 1 & 100 \\
\hline University of Tennessee Knoxville & 7 & 1 & 1 & 89 \\
\hline University of Wisconsin Milwaukee & 7 & 0 & 1 & 51 \\
\hline City University of New York Baruch & 6 & 0 & 0 & 28 \\
\hline Long Island University & 6 & 0 & 1 & 19 \\
\hline Northern Illinois University & 6 & 0 & 0 & 42 \\
\hline Purdue University & 6 & 1 & 0 & 66 \\
\hline University of Kentucky & 6 & 1 & 1 & 92 \\
\hline Victoria University of Wellington & 6 & 0 & 0 & 7 \\
\hline
\end{tabular}


Correlation analysis was conducted for each of the three variables - ARL membership, presence of a PhD-granting library school, and number of professional staff-to determine if these variables influence the rankings of one to thirty-six (the original thirtyeight less Simmons College and Suffolk University). Correlation coefficients were, however, surprisingly low for each of the three variables. The correlation coefficient for the presence of a $\mathrm{PhD}$ program was 0.1588 - so low as to indicate virtually no relationship to the ranking among the thirty-six libraries. Being an ARL member had a stronger, but still weak, correlation coefficient of 0.3217 . The size of the professional staff did not, moreover, correlate with ranking. There was only a 0.3737 correlation coefficient, suggesting that there is little relationship between the number of library professionals in a library and the number of times they authored in the five journals.

While large ARL member libraries predominate the top ten percent, the number of professionals seems to have little impact as to whether the institution is ranked first or thirty-sixth. There may be significant differences, however, among the publication rates of practitioners and library school faculty that this analysis does not capture. Library school faculty are not typically included in ARL counts of professionals which may explain the weak correlation coefficient. It is more likely, however, that local culture or circumstances determine how actively a faculty might publish and which journals they might target. It may also be that publication activity is a highly individual activity and that many of the higher occurrences for institutions are due to one or two individuals.

\section{Conclusion}

In their 2006 study, Wiberley et al. found that "the twenty most productive libraries published more than 10 percent of all refereed articles in the thirty-two journals"(p. 214 ) they examined. Similarly, this study found that about ten percent of libraries accounted for forty-two percent of the author affiliations in the five highest impact journals between 2000 and 2005. These two studies, of course, are not directly comparable because of the differences in journals examined and the years covered. Yet the similarities between the results are striking. In fact, thirteen of Wiberely et al.'s twenty highest producing libraries are on the list of Table 4. John Budd's 2006 study of institution-wide productivity, however, shares only nine of twenty institutions listed in Table 4, suggesting that a university's culture regarding publications does not always translate to high publication rates for libraries (Budd, 2006).

This study examined the recent articles in high-impact library journals to determine any patterns in the institutional affiliation of the primary and secondary authors. It used a publication count from highly cited journals to rank libraries as to their publication activity. The findings, that about ten percent of institutions account for over forty percent of the primary and secondary author affiliations, suggest that a handful of North American libraries regularly produce high-quality scholarship. What, then, do these libraries have in common? According to this research - not a lot. All of the top ten percent are academic libraries and most are ARL members. However large universities and small colleges are represented in the top ten percent and both private and public institutions are also represented. There are libraries with over 200 professional staff and others with fewer than fifty. There are libraries with ready access to PhD-granting library 
schools and those without. Some libraries offer tenure, while others do not. It would, of course, be surprising if there were easily defined characteristics that identified such libraries. While it is tempting to speculate why these libraries are in the top ten percent, this study does not provide sufficient data on which to base meaningful analysis. Instead, follow-up research is necessary to identify why librarians from these institutions are regularly represented in high-impact journals. A longitudinal study to assess how the institutions in the top ten percent have changed throughout time would be an important next step.

As with any study of research output, there are limitations in the analysis. How impact factors relate to quality has been discussed at length. In addition, however, limiting the analysis to journals excludes those libraries whose researchers regularly publish monographs. Also excluded - and of increasing importance - is research published on the Web. In any case, limitations within the methodologies of any of these studies preclude absolute accuracy in the results. The only realistic expectation from these studies is to obtain an approximation of whether a program ranks in the top, middle, or bottom of research productivity. Nonetheless, such studies are important components in understanding the vitality of the "library science" discipline and identifying those most successful in pursuing their research agendas. And, with the current emphasis on assessment, such studies are likely to be ever more necessary.

\section{References}

American Library Association. (2006). Search the ALA Directory of Accredited Programs: Limit to Schools Offering the PhD. Retrieved April 4, 2008 from http://www.ala.org/Template.cfm?Section=lisdirb\&Template=/cfapps/lisdir/lisdir_sea $\underline{\text { rch.cfm }}$

Association of College and Research Libraries. (2005a). 2004 Academic Library Trends and Statistics for Carnegie Classification: Doctorate-Granting Institutions. Chicago: ACRL.

Association of College and Research Libraries. (2005b). 2004 Academic Library Trends and Statistics for Carnegie Classification: Master's Colleges and Institutions Baccalaureate Colleges. Chicago: ACRL.

Association of Research Libraries. (2006a). ARL Member Libraries' Information Services. Retrieved April 4, 2008 from http://www.arl.org/members.html.

Association of Research Libraries. (2006b). Statistics and Measurement Program; ARL Statistics WWW Interactive Edition Ranked Lists. Retrieved September 27, 2008 from http://fisher.lib.virginia.edu/cgi-local/arlbin/arl.cgi?task=setuprank;

Bates, M.J. (1998). The Role of Publication Type in the Evaluation of LIS Programs. Library \& Information Science Research, 20, 197. 
Blixrud, J.C. (2000). SPEC Kit 257: The M.L.S. Hiring Requirement. Association of Research Libraries, Office of Leadership and Management Services.

Budd, J.M. (1995). Faculty Publishing Productivity: An Institutional Analysis and Comparison with Library and Other Measures. College \& Research Libraries, 56, $547-54$

Budd, J.M. (1999). Increases in Faculty Publishing Activity: An Analysis of ARL and ACRL Institutions." College \& Research Libraries, 60, 308-15.

Budd, J.M. (2000). Scholarly Productivity of U.S. L.I.S. Faculty: An Update. Library Quarterly, 70, 230-45.

Budd, J.M. (2006). Faculty Publishing Productivity: Comparisons Over Time. College \& Research Libraries, 67, 230-9.

Hart, R. (1999). Scholarly Publication by University Librarians: A Study at Penn State. College \& Research Libraries, 60, 454-62.

Joint Committee on Quantitative Assessment of Research. (2008). Citation Statistics: A Report from the International Mathematical Union (IMU) in Cooperation with the International Council of Industrial and Applied Mathematics (ICIAM) and the Institute of Mathematical Statistics (IMS). Retrieved September 27, 2008 from International Mathematical Union: http://www.mathunion.org/publications/report/

Kohl, D., and Davis, C.H. (1985). Ratings of Journals by ARL Library Directors and Deans of Library and Information Science Schools." College \& Research Libraries, 46, 40-7.

Lokman, M. and Spurgin, K. (2005). Ranking the Research Productivity of Library and Information Science Faculty and Schools: An Evaluation of Data Sources and Research Methods. Journal of the American Society for Information Science and Technology, 56, 1314-31.

Nisonger, T.E. (2004). The Benefits and Drawbacks of Impact Factor for Journal Collection Management in Libraries. Serials Librarian, 47, 57-75.

Nisonger, T.E. and Davis, C.H. (2005). The Perception of Library and Information Science Journals by LIS Education Deans and ARL Library directors: A Replication of the Kohl-Davis Study. College \& Research Libraries, 66, 341-77.

Thomson Scientific. (2006a). Impact Factor. Retrieved April 3, 2008, from http://jcr1.isiknowledge.com/JCR/help/h impfact.htm 2005.

Thomson Scientific. (2006b). 2005 JCR Social Sciences Edition. Journal Summary List: Information Science and Library Science. Retrieved April 4, 2008 from

$\operatorname{Pg} 18$

LIBRES ISSN 1058-6768 Volume 18, Issue 2, September 2008 
http://portal.isiknowledge.com/portal.cgi/jcr?Init=Yes\&SID=E1p5IJDm@,f21LpngEh $\underline{\mathrm{G}}$.

Thomson Scientific. (2006c). Scope Notes 2005 Social Science Categories: Category Name, Information Science and Library Science. Retrieved April 4, 2008 from http://portal.isiknowledge.com/portal.cgi/jcr?Init=Yes\&SID=E1p5IJDm@f21LpngEh G.

Thomson Scientific. (2006d). How to Calculate a Five-Year Impact Factor. Retrieved April 4, 2008 from http://jcr1.isiknowledge.com/JCR/help/h fiveyr if.htm\#five year if.

Weller, A.C., Hurd, J.M., and Wiberley, S.E. (1999). Publication Patterns of U.S. Academic Librarians from 1993 to 1997. College \& Research Libraries, 60, 352-62.

Wiberley, S.E., Hurd, J.M., and Weller, A.C. (2006). Publication Patterns of U.S. Academic Librarians from 1998 to 2002. College \& Research Libraries, 67, 205-16.

Zainab, A.N. (2000). Publication Productivity, Focus on Institutional, Collaborative and Communicational Correlates: A Review of the Literature. Malaysian Journal of Library \& Information Science, 5, 53-94.

Zemon, M. and Bahr, A.H. (1998) An Analysis of Articles by College Librarians. College \& Research Libraries, 59, 422-32.

Zemon, M. and Bahr, A.H. (2000) Collaborative Authorship in the Journal Literature: Perspectives for Academic Librarians Who Wish to Publish. College \& Research Libraries, 61, 410-19. 